\title{
$\mathrm{WiFi} \mathrm{AP}$ 성능 향상을 위한 무선 자원 관리 최적화
}

정 길 현*

\section{RRM Optimization for the Throughput Enhancement of WiFi AP}

\author{
Kil Hyun Jeong *
}

\section{요 약}

최근 스마트 이동 단말기기의 급속한 보급과 더불어 많은 수의 WiFi Access Point (AP)가 설치되어 사용되고 있으며, $\mathrm{WiFi} \mathrm{AP}$ 의 증가는 $\mathrm{AP}$ 간의 상호 간섭에 의한 트래픽 처리 성능의 저하를 발생시킨다. 이런 현상은 기존 $\mathrm{WiFi}$ 망에 활용할 수 있는 트래픽 성능을 향상시키기 위한 방법을 요구한다.

본 연구에서는 트래픽 성능을 향상시키기 위하여 $\mathrm{AP}$ 의 무선 자원 관리 (RRM : Radio Resource Management)를 최적화하기 위한 채널 할당 방법과 분산형 Wireless LAN (WLAN) 에서의 트래픽 성능 향상 방법에 대하여 연구하였다. 그 결과, $\mathrm{AP}$ 단독으로 실행되어 기존방식의 할당 오류를 개선하고 실행속도를 증가시 킬 수 있었다.

- Keywords : WiFi AP, 무선자원관리, 무선 LAN

\begin{abstract}
In these days, with the diffusion of mobile equipments, the number of WiFi Access Point (AP) is increasing, and the growth of WiFi AP causes the throughput degradation due to interferences between APs. This recent phenomenon demands the method able to be utilized with current WiFi network to improve the throughput of Wireless LANs.

This paper studied the channel assignment method and several throughput enhancement methods to optimize Radio Resource Management (RRM) for distributed infrastructure WLANs. As

- 투고일 : 2012. 11. 24, 심사일 : 2012. 11. 28, 게재확정일 : 2012. 12. 14

* 장안대학교 IT학부 인터넷정보통신과 (Dept. of Internet Communication, Jangan University)

※ 이 논문은 장안대학교 2012학년도 자체연구비 지원에 의하여 연구되었음.

2012 년 한국정보전자통신기술학회 추계종합학술대회에서 발표한 논문(“WiFi AP 성능 향상을 위한 채널 할당 연구”)을 확 장한 것임.
\end{abstract}

- 제 1 저자 : 정길현 
a result, it was able to put $\mathrm{AP}$ independently, improve older allocation error, and improve execution speed.

- Keywords : WiFi AP, Radio Resource Management (RRM), Wireless LAN (WLAN)

\section{I. 서 론}

최근 스마트 이동 단말 기기의 사용이 증가하면서 $\mathrm{WiFi}$ 무선데이터 서비스에 대한 수요 급증과 함께 많은 수의 $\mathrm{WiFi}$ $\mathrm{AP}$ 가 설치되어 운용되고 있다.

이러한 $\mathrm{AP}$ 들은 사용자에 의해 임의로 설치하는 경우가 대 부분을 차지하므로 동일한 인접 지역 내에서 $\mathrm{AP}$ 간 상호 간섭에 의한 트래픽 성능 저하가 발생하고 있다. 보고에 따르 면 미국의 경우 절반 이상의 $\mathrm{AP}$ 들이 3 개 이상의 인접 $\mathrm{AP}$ 에 의해 간섭을 받는 환경 하에 있고 우리나라의 강남역, 삼성역 등지의 인구 밀집 지역에서는 80 개 이상의 인접 $\mathrm{AP}$ 들이 존 재하는 것으로 나타나있다. [1-4]

이러한 상황은 ISM (Industrial, Scientific and Medical) 밴드를 사용 하는 IEEE 802.11 표준의 최초 목 적이 독립된 지역 내의 사용자들에게 무선 LAN 기능을 제공 하고자 제정된 규격이었고 당시의 규격에서 미처 예상하지 않 았던 상황으로서 상호 간섭 상황을 최소화하고 성능을 최대 화하기 위한 방안의 강구가 필요하게 되었다.

IEEE 802.11 규격에서는 상호 간섭 환경 하에서 CSMA/CA (Carrier Sense Multiple Access with Collision Avoidance) 방식을 사용하여 간섭 상황에서 상호 충돌을 회피하고 있다. [4] 그러나, 간섭이 있는 조건 하에서 충돌 (collision)이 발생하면 백-오프 (back-off) 시간 동안 기다리고 충돌 횟수에 따라 백-오프 타이머 시간이 증가하므 로 무선 채널의 점유율은 높아지면서 실제 유효한 트래픽 성 능은 저하하게 된다. $\mathrm{CSMA} / \mathrm{CA}$ 방식뿐만 아니라 $\mathrm{WiFi}$ 기 기는 ISM 밴드의 전자레인지, 블루투스 기기 등으로 부터의 잡음의 영향을 받아서 성능이 저하되기도 한다.

이러한 성능 저하는 고속의 멀티미디어 트래픽이 증가하는 추세에서 사용자들로 하여금 많은 불편을 겪게 하고 있다. 이 를 해결하기 위해 최근에 많은 연구가 이루어지고 있으며 주 로 무선 $\mathrm{AP}$ 제어기 ( $\mathrm{AC}$ : $\mathrm{AP}$ Controller)를 이용한 중앙관 리형 $\mathrm{WiFi}$ (managed $\mathrm{WiFi}$ ) 망을 기반으로 이루어지고 있 다.[5-7] 이러한 중앙관리형 $\mathrm{WiFi}$ 는 캠퍼스나 대형 빌딩용
독립형 기업 $\mathrm{WiFi}$ 망을 기준으로 구현되어 $\mathrm{WLAN}$ (Wireless LAN) 망의 대부분을 차지하는 일반적인 분산 구 조의 $\mathrm{WiFi}$ 망에 적용하는 것이 불가능하다. 즉, $\mathrm{AP}$ 로 부터 다른 채널의 망 간섭 상태를 보고 받아서 전체 망의 채널 할 당을 최적화하는 방식은 각각의 $\mathrm{AP}$ 를 관리하고 제어하는 $\mathrm{AC}$ 의 존재가 반드시 필요하다. 이러한 제약을 회피하기 위해 분 산된 $\mathrm{AP}$ 망의 가변적인 채널 할당을 가능하게 하는 방식이 Leith 등에 의해 제안되었다. [8] 그러나 이 방식은 채널의 상태를 측정하기 위해 단말로부터 채널 상태를 보고 받아야 하므로 단말기에 측정용 프로그램이 항상 운용되어야 하기 때 문에 기존 단말의 호환성 문제, 배터리의 소모 전력 증가 등 실용성에는 문제가 있는 방식이다. 본 연구에서는 기존 $\mathrm{WiFi}$ 망에 그대로 활용할 수 있는 최적 채널 할당 방법과 간섭 상 황 하에서 트래픽 성능을 향상시키기 위한 방법에 대하여 고 찰하였다.

본 논문의 구성은 다음과 같다. 2장에서는 802.11 표준의 데이터 통신 방식에 대해 기술하고 3장에서는 중앙관리형 채 널 최적화 알고리즘, 4 장에서는 분산형 채널 할당 방법 등을 기술하고 5 장에서 알고리즘의 개선 방법과 그 결과에 대하여 설명하였다.

\section{IEEE 802.11}

IEEE 802.11 규격은 ISM 무선랜 서비스를 위한 국제 표준 규격으로서 전 세계적으로 가장 일반화되어 사용 중인 규격으로 IEEE $802.11 \mathrm{a} / \mathrm{b} / \mathrm{g} / \mathrm{n}$ 등의 표준이 제정되었으며 최근에도 새로운 서비스를 위한 수정규격이 계속 제정되고 있 다. 또한, IEEE 802.11 망에서는 3G, WiBro, LTE 등의 이동통신과는 달리 무선 미디어를 공유하여 사용한다. 즉 데 이터 프레임과 제어 프레임의 상하 양방향 링크는 동일한 채 널을 사용한다.

802.11 망에서는 $2.4 \mathrm{GHz}$ 또는 $5 \mathrm{GHz}$ 의 주파수 영역을 사용하며 $2.4 \mathrm{GHz}$ 대역의 경우 11 개의 채널, $5 \mathrm{GHz}$ 의 경우 36 번부터 140 번까지의 채널로 구성되어있다. WiFi 망의 접 속 방식은 잘 알려진 $\mathrm{CSMA} / \mathrm{CA}$ 프로토콜을 사용하고 있다. 
이 프로토콜에서는 상호 충돌을 회피하기 위하여 수 마이크로 초의 백-오프 시간 동안 채널의 가용 여부를 판단하고 데이터 를 송신한다. 백-오프 시간은 부터 $C W$ (Contention Window)까지 랜덤한 수의 타임 슬롯 (time slot)의 배수 시간으로 되어 있다. 이 시간의 범위는 식(1)과 같이 표시할 수 있다.

$$
W_{\mathrm{min}} \leq C W \leq C W_{\max }
$$

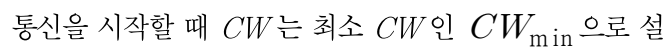
정되지만 충돌이 발생하면 2 의 배수로 증가 되어 최대 $C W$ 시간인 $C W_{\mathrm{max}}$ 까지 늘어 날 수 있다.

$$
C W=\min \left(2^{\text {nit }+ \text { collisions }}-1, C W_{\max }\right)
$$

프레임 전송이 성공하면 $C W$ 시간은 최소 $C W$ 시간으로 리셋 된다. $C W$ 의 최소값과 최대값은 각각 31 과 1023 이며 타임 슬롯의 단위는 9 마이크로초 또는 20 마이크로초이다. 이러한 $\mathrm{CSMA} / \mathrm{CA}$ 프로토콜은 동일 미디어를 공유하므로 채 널의 부하, 충돌, 간섭 등에 의해 통신 성능이 저하되고 지연 이 발생하게 된다. $\mathrm{CSMA} / \mathrm{CA}$ 방식의 충돌 회피 과정은 그림 1 과 같다.

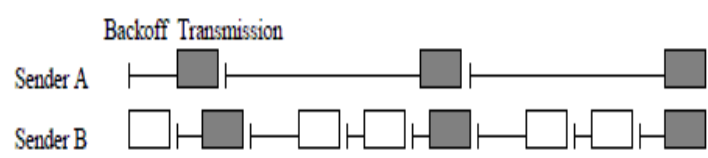

그림 1. $\mathrm{CSMA} / \mathrm{CA}$ 의 충돌 회피 과정

Fig. 1 Collision Avoidance of CSMA/CA

\section{III. 중앙관리형 WiFi (managed WiFi) 채널 할당 알고리즘}

$\mathrm{AP}$ 간의 채널 할당을 최적화함으로서 인접한 단말과의 상 호 간섭, 채널 부하, 충돌 등을 줄여서 무선 구간의 활용성을 증대할 수 있다.

최적화된 채널 할당 알고리즘은 그림 2 와 같은 WLAN 망 에서 각 노드와 각 노드의 무선장치의 채널 할당을 통해 무선 망 간섭을 최소화 시키는 과정이다.

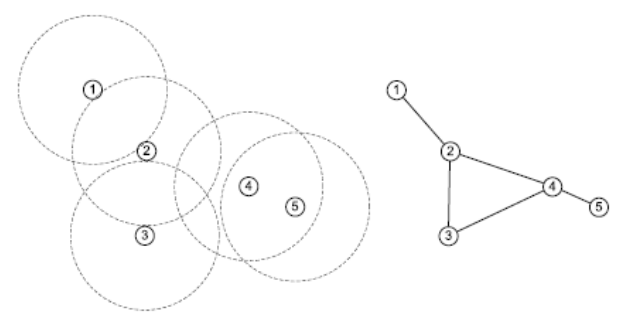

그림 2. AP망과 그래프 표현

Fig. 2 AP network and representing Graph

Leung[5] 등은 중앙관리형 WLAN 망에서 각 $\mathrm{AP}$ 의 최적 화 채널 할당 알고리즘을 발표하였다. 이 방식에서는 발견적 탐색 (heuristic search) 기법으로 최적화 속도를 증가시키 고 성능 적으로 양호한 결과를 얻을 수 있었다. 이 알고리즘 에서는 최대간섭이 발생하는 병목 $\mathrm{AP}$ 의 주변 $\mathrm{AP}$ 들의 채널 할당을 변경하는 방법을 반복하여 최종결과를 얻는데 다음과 같이 5 단계 과정으로 되어있다.

(1) 전 $\mathrm{AP}$ 들의 채널을 임의로 할당한다.

(2) 병목 $\mathrm{AP}$ 를 선택한다. 이 때 채널 사용률을 $V$ 라고 한 다.

여러 개의 경우 무작위로 한 개를 선택한다.

(3) 병목 $\mathrm{AP}$ 의 채널을 $k$ 라고 할 때 주변 $\mathrm{AP} j$ 의 채널을 $n(n \neq k)$ 로 변경하고 채널 사용률 $W$ 를 다시 계산한 다.

(4) 채널 사용률 $V$ 와 $W$ 를 비교 실행한다.

i) $W \chi_{V}$ 이면 $V$ 를 $w$ 로 대체하고 (2)를 다시 실행한다.

ii) $W=V$ 이면 $\delta$ 의 확률로 $V$ 를 $W$ 로 대체하고 (2)를 다 시 실행한다.

iii) $W\rangle_{V}$ 이면 부분적 최적화가 달성되어 (5)를 실행한 다.

(5) 위의 (1) (4)를 새로운 할당으로 다시 실행하여 (4)에 따 라서 최선의 결과를 선택한다.

그림 3 은 21 개의 $\mathrm{AP}$ 와 3 개의 독립채널이 있는 경우 위에 서 설명한 알고리즘을 적용한 결과이다. 이 그림에서 모든 $\mathrm{AP}$ 간의 채널 간섭이 발생하지 않도록 최적화되었음을 알 수 있다. 


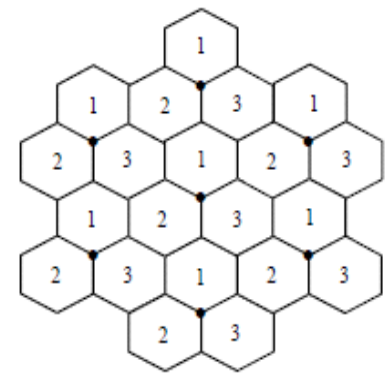

그림 3. 21개 AP망의 최적화 채널 할당.

Fig. 3 Optimizing Channel Allocation of 21 APs

이 알고리즘은 중앙관리형 $\mathrm{AP}$ 제어장치인 $\mathrm{AC}$ 에서 알 고리즘이 수행되는 기업형 중앙제어 WLAN 망에 적합한 방식이며 자기 망 이외의 다른 망이 존재하는 경우 다른 망으로 부터의 간섭을 고려하지 않을 뿐 아니라 노드의 숫 자가 늘어나면 최적의 할당 결과 획득에 실패할 수 있는 문제가 있다. 그렇지만, 이런 문제는 MMSE (Minimum Mean Square Error)를 활용한 개선된 알고리즘을 사용 하면 언제나 최적화된 결과를 얻을 수 있음을 확인하였다.

\section{IV. 분산형 $\mathrm{AP}$ 동적 채널할당 방법}

$\mathrm{AC}$ 가 존재하는 일반적인 WLAN 망에서 동적으로 최 적화된 채널을 할당하는 방법이 Ihmig[9] 등에 의하여 발 표되었다. 이 알고리즘은 $\mathrm{AP}$ 단독으로 실행되므로 주변 $\mathrm{AP}$ 가 다른 관리자에 의해 운용되는지에 상관없이 최적화 된 채널을 할당할 수 있다. 이 알고리즘은 감시모듈, 실행 모듈, 채널전환모듈 등 3 개의 요소로 구성되어 있다. 감시 모듈은 각 $\mathrm{AP}$ 의 주어진 채널에서 채널 부하를 지속적으로 감시한다. 이 때 채널 부하는 시간에 따라 변화가 심하기 때문에 식(3)과 같이 이동평균을 이용하여 정규화 하여 사 용한다.

$$
=\alpha \bar{x}_{k-1}+(1-\alpha) x_{k,} \quad \alpha=\begin{gathered}
n \\
n+1
\end{gathered}
$$

각 채널의 정규화 된 채널 부하는 채널별 부하테이블 (load table)에 저장한다.

평가모듈은 채널변환을 위한 평가를 수행하는 모듈로서

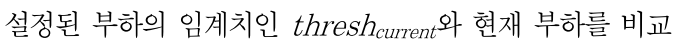
하여 채널 변경여부를 결정한다. 최초 시작 시에는 $50 \%$ 의 채널 부하를 임계치 thresh $h_{\min }$ 으로 정의하고

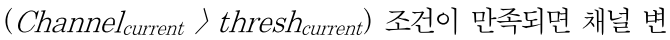
경이 실행된다. 채널 변경은 모든 부하테이블 엔트리들의 업데이트가 완료되었으면 가장 작은 엔트리를 가진 채널을 선택한다. 그 다음 두 번째로 작은 엔트리를 thresh $h_{\text {current }}$ 로 놓고 채널을 변경하고, $t_{\text {hold }}$ 시간동안 머무른다. 만약, 모든 부하테이블 엔트리들의 업데이트가 완료되지 않았다 면 가장 오래된 엔트리를 가진 채널을 선택한다. thresh $h_{\text {current }}=$ thresh $_{\min }$ 으로 정의하고, 채널을 변경한 후 $t_{\text {hold }}$ 시간동안 머무른다. 그림 4 는 이와 같은 채널 변경 알고리즘의 수행 과정을 순서도로 나타내었다.

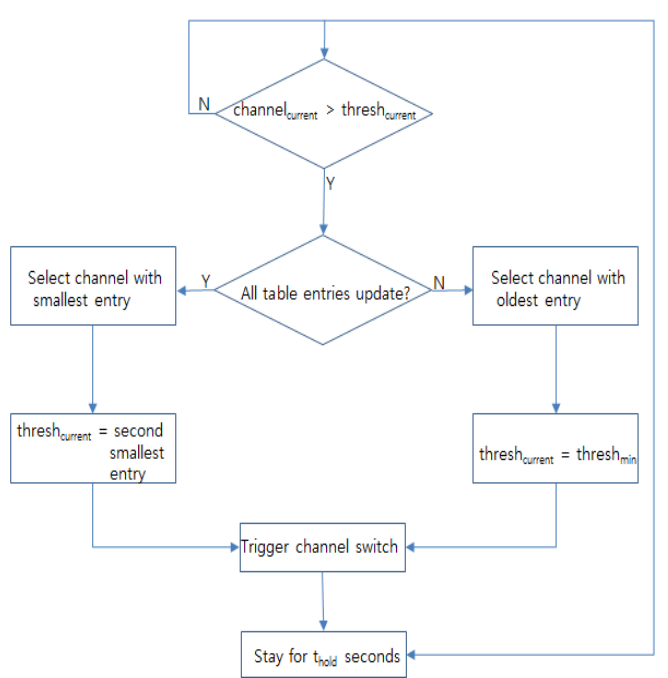

그림 4. 채널선택 알고리즘 순서도

Fig. 4 The Flow chart of Channel Selection Algorithm

\section{V. 알고리즘 개선 및 결과}

IV장에서 언급한 채널 할당 알고리즘은 단순하여 AP에 적 용이 용이하며 $\mathrm{AP}$ 의 하드웨어 변경이나 단말기에서 추가적인 프로그램 실행이 필요 없는 유용한 알고리즘이다. 최적화 경 우에 대비해서 $95 \%$ 정도의 성능을 보여주며 최적화 채널 할 당 수렴특성을 보인다. 그러나 실행과정에서 그림 5 와 같은 채널 할당의 오류가 발생할 수 있으며 최적화 할당으로 천이 가 되지 않고 고정되는 경우가 생긴다. 


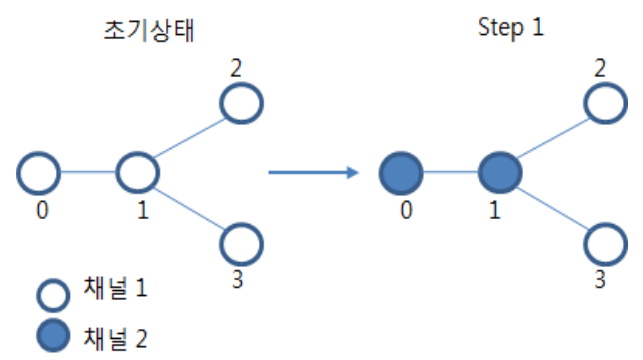

그림 5. 채널 할당 오류의 예

Fig. 5 The Example of Channel Allocation Error

그림 5 는 2 개의 주파수 (채널1, 채널2)가 할당되는 예로 서 $\mathrm{APO}$ 는 초기에 1 번 채널로 할당되었다가 초기 설정된 $T h r e s h_{m i n}$ 과 비교하여 현재의 부하가 크므로 채널 2 번으로

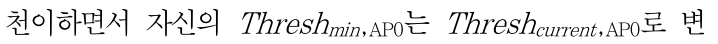
경 저장된다. 마찬가지로 $\mathrm{AP} 1$ 은 $\mathrm{AP} 2$ 와 간섭까지 추가되어 2 번 채널로 천이하면서 Thresh $h_{\min , \mathrm{AP1}}=$ Thresh $h_{\text {current }, \mathrm{AP} 1}$ 으 로 변경된다. 이 상황에서 최적화되지 않는 채널 배치 상태에 서 고정되어 버리는 경우가 발생한다.

이를 해결하기 위해서 개선된 알고리즘에서는 초기 임계 치 테이블을 작성할 때 임의의 지정된 값을 저장하지 않고 모 든 채널에 대해 부하량을 검사해서 작성, 저장하여 초기에 최 적의 채널을 선택하게 하고 주어진 시간이 경과하면 채널 변 경을 강제로 실행하게 함으로서 이 문제를 해결할 수 있다. 그림 6 에는 기존 알고리즘과 개선된 방식의 수렴속도 비교를 나타내었다. 즉, 노드 수를 변경하면서 각 알고리즘이 최적화 채널을 할당할 때까지의 실행횟수 들의 평균값을 구한 결과 이다.

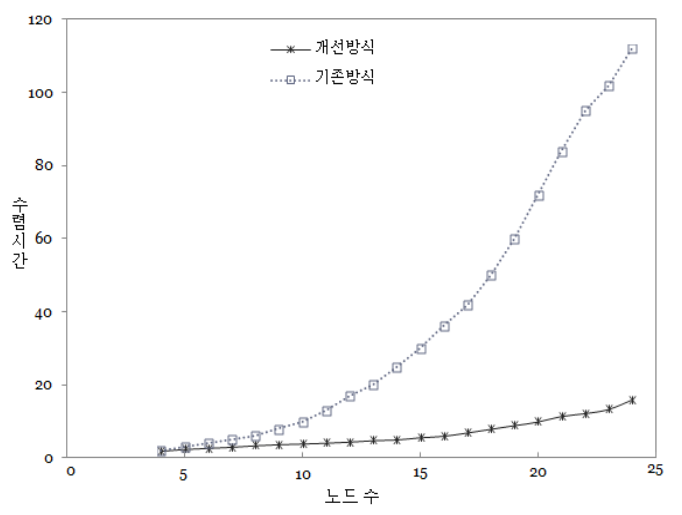

그림 6. 수렴속도 비교 Fig. 6 The Comparison of Convergence Rate
그림에서 보는 바와 같이 개선된 알고리즘은 노드 수가 증 가하여도 최적의 채널 할당에 요구되는 수렴시간이 감소한다.

\section{VI. 결 론}

본 연구에서는 일반적인 $\mathrm{WiFi}$ 망에서 사용할 수 있는 최 적화 채널 할당 알고리즘에 대하여 연구하였다. 이 알고리즘 은 부가적인 중앙관리장치와 측정을 위하여 단말기에서 실행 하는 프로그램의 도움 없이 AP 단독으로 수행할 수 있는 개 선된 분산형 채널 할당 알고리즘을 제시하였다. 그 실행 결과 노드 수 증가에 따른 수렴시간의 감소를 보였다. 따라서, 제 시된 알고리즘은 기존 방식의 할당오류를 개선하고 실행속도 를 증가시킬 수 있다. 좀 더 적극적인 간섭제거를 위해서는 각 $\mathrm{AP}$ 의 전력제어를 포함한 중앙관리장치의 사용이 바람직하 다. 그러나, 이 같은 $\mathrm{WiFi}$ 의 간섭제거 알고리즘은 중앙관리 장치의 도움 없이 최적의 채널을 얻을 수 있으므로 기존의 $\mathrm{WiFi}$ 망에 용이하게 적용할 수 있다.

\section{참고문헌}

[1] Aditya Akella, Glenn Judd, Srinivasan Seshan, and Peter Steenkiste., "Self-management in chaotic wireless deployments", In MobiCom '05: Proceedings of the 11th annual international conference on Mobile computing and networking, pp. 185 - 199, Cologne, Germany, 2005.

[2] Kil Hyun Jeong., "The Implementation of DDC for the WLAN Receiver", Journal of the Korea Society of Computer and Information, Vol.17, No.2, pp.113-118, 2012.

[3] http://en.wikipedia.org/wiki/IEEE_802.11

[4] IEEE Standard for Information technology Telecommunications and information exchange between systems - Local and metropolitan area networks - Specificrequirements - Part 11: Wireless LAN Medium Access Control (MAC) and Physical Layer (PHY) Specifications. IEEE Std 802.11TM-2007.

[5] K. Leung and B. Kim., "Frequency assignment for IEEE 802.11 wireless networks", Proc. 58th IEEE Vehicular Technology Conference, Vol.3, 
pp.1422-1426, Oct., 2003.

[6] Arunesh Mishra, Suman Banerjee, William Arbaugh., "Weighted Coloring based channel Assignment for WLANs", ACM SIGMOBILE Mobile Computing and Communications Review, Vol.9, No.3, pp. 19-31, 2005.

[7] Marcel Wiilliam Rocha da Silva, José Ferreira de Rezende., "A Dynamic Channel Allocation Mechanism for IEEE 802.11 Networks", ITS 2006, pp.225-230, FORTALEZA-CE, BRAZIL, Sept., 2006.

[8] D.J.Leith, P.Clifford, V.Badarla, D.W.Malone, "WLAN Channel Selection Without Communication", Computer Networks, Vol.56, No.4, pp.1424-1441, March, 2012.

[9] M.Ihmig and P.Steenkiste., "Distributed dynamic channel selection in chaotic wireless networks", 13th European Wireless Conference, Paris, France, pp.1-7, April, 2007.

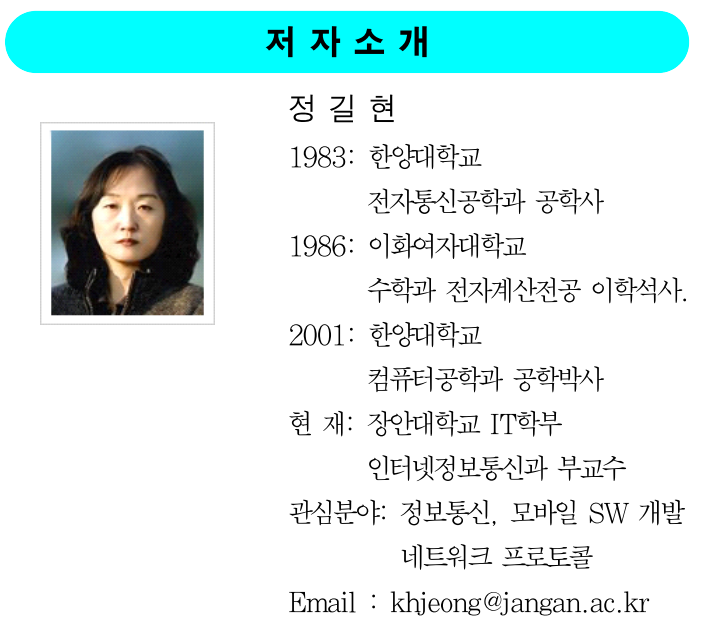

